\title{
Seismic Performance of a Souring Sluice Considering Foundation Characters
}

\author{
Cong Zeng, Dongxue Hao, Liqun Hou, Chuncheng Liu \\ Department of Architectural Engineering, Northeast Dianli University, Jilin, 132012, China
}

\begin{abstract}
To study the seismic performance of a souring sluice, a 3D finite element model was established by considering the foundation characters. Mode-superposition response spectrum method was used to precede the seismic calculation. It is concluded that the seismic performance can satisfy the specification. Furthermore, the weak parts which are required to be reinforced were indicated.
\end{abstract}

Keywords- foundation character; souring sluice; seismic performance.

\section{INTRODUCTION}

A low water head, mass flow and run of river middle-sized hydropower station are located in Yunnan province, which is in the middle stage of main stream of Nujiang river. The maximal height of dam is $45.0 \mathrm{~m}$. The installed capacity is $5 \times 36 \mathrm{MW}$. The storage capacity is $2540 \times 104 \mathrm{~m}^{3}$. As one of the most important constructions, the souring sluice is a reinforced concrete structure, which is based on the riverbed alluvium. The length along the river is $41 \mathrm{~m}$, and the width of sluice gate is $11 \mathrm{~m}$. There are totally 6 sluice chambers in the right bank sluice, and permanent construction joints are set in the middle of sluice pier between each chambers, therefore, the whole souring sluice can be divided into 3 sections.

6 sluice gates are set in the downstream side of each sluice, which is open and close by winches fixed in the top of chamber frame. The loading capacity of open/close winches are $2 \times 3200 \mathrm{kN}$, and the weight is $100 \mathrm{t}$. The height of main open/close frame is $36.4 \mathrm{~m}$. The bearing members are 4 columns in the size of $1.4 \mathrm{~m} \times 1.4 \mathrm{~m}$. There are 5 stories in the frame, only ring beams are set in the first 3 stories without floors, and the 4th floor is open/close winch room with the floor height of $7.9 \mathrm{~m}$, and the 5 th floor is the roof. The height of subsidiary open/close frame is $14.5 \mathrm{~m}$, which is used to install the bulkhead gate drive by hoist, the hoist floor height is $6 \mathrm{~m}$, and the underpart height is $8.5 \mathrm{~m}$. The three views of souring sluice are shown in Fig1.

The site of souring sluice is located in the region of 7 degree seismic fortification intensity, which is in the borderline between 7 degree and 8 degree. The peak value of earthquake acceleration is $0.15 \mathrm{~g}$, predominant period is $0.3 s^{[1]}$. The stiffness of upper open/close frame is obviously lower than the bottom sluice pier. Moreover, a heavy winch is set in the top of relatively flexible frame which may cause whipping effect. The uneven distribution of mass and stiffness, as well as the site location is the earthquake-active province Yunnan, the seismic performance of the souring sluice is significant.

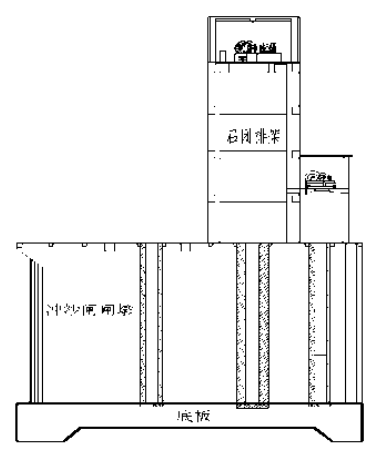

(a)Side elevation

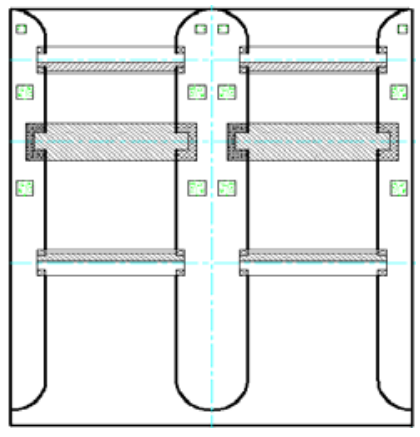

(b) Top view

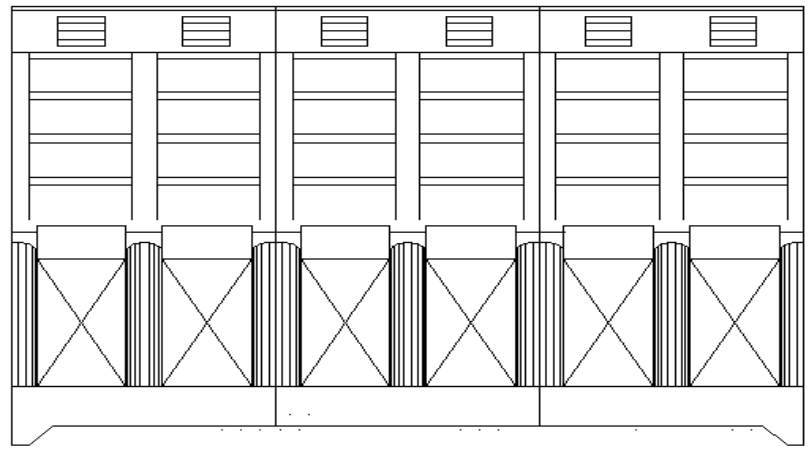

(c) Front elevation

Figure 1. Three views of souring sluice

\section{FOUNDATION CHARACTERS}

The foundation of souring sluice is the riverbed alluvium. To guarantee the seepage control stability and sliding stability, key walls are $2.0 \mathrm{~m}$ deeply set in the upstream and downstream side of the baseboard. Weak-weathered rock is beneath the riverbed alluvium, the parameters of foundation are listed in table 1. It is obviously that the foundation characters may markedly affect the upper souring sluice ${ }^{[2]}$. Foundation model is considered in the establishment of the entire ANSYS model. 
TABLE I. FOUNDATION MECHANIC PARAMETERS

\begin{tabular}{|c|c|c|}
\hline Foundation Characters & Geological Suggest & Adopt \\
\hline $\begin{array}{l}\text { friction coefficient between alluvium } \\
\text { and concrete }\end{array}$ & $0.50 \sim 0.55$ & 0.45 \\
\hline Bearing capacity of alluvium & $0.5 \sim 0.8 \mathrm{MPa}$ & $0.65 \mathrm{MPa}$ \\
\hline Volume weight of alluvium & $21 \mathrm{kN} / \mathrm{m}^{3}$ & $21 \mathrm{kN} / \mathrm{m} 3$ \\
\hline deformation modulus of alluvium & $45 \sim 50 \mathrm{MPa}$ & $50 \mathrm{Mpa}$ \\
\hline $\begin{array}{l}\text { Shear friction coefficient between } \\
\text { WWR and concrete }\end{array}$ & $0.55 \sim 0.70$ & 0.5 \\
\hline $\begin{array}{l}\text { shearing cohesion between WWR } \\
\text { and concrete }\end{array}$ & $0.30 \sim 0.40 \mathrm{MPa}$ & $0.3 \mathrm{MPa}$ \\
\hline Bearing capacity of WWR & $0.8 \sim 1.0 \mathrm{MPa}$ & $0.7 \mathrm{MPa}$ \\
\hline Volume weight of WWR & $25 \sim 30 \mathrm{kN} / \mathrm{m}^{3}$ & 29 \\
\hline deformation modulus of WWR & $2 \sim 3 \mathrm{GPa}$ & $2.9 \mathrm{GPa}$ \\
\hline
\end{tabular}

\section{FINITE ELEMENT SIMULATION WITH ANSYS}

\section{A. Parameters and FEM model}

The middle opening section of the souring sluice was selected as the typical section, which is modeled by ANSYS. The model is including sluice chamber, sluice gate, open/close frame, baseboard and the foundation with chamber height. Foundation, baseboard and sluice chamber are modeled by the so-called SOLID65 finite element, and the open/close frame was modeled by BEAM44 element, and the SHELL63 element was used to simulate the sluice gate. The material parameters and selected elements are summarized in Table 2.

TABLE II. MATERIAL PARAMETERS AND SELECTED ELEMENT

\begin{tabular}{lcccc}
\hline Part & $\begin{array}{c}\text { Elasticity } \\
\text { modulus } \\
(\mathrm{Mpa})\end{array}$ & $\begin{array}{c}\text { Poisson's } \\
\text { ratio }\end{array}$ & $\begin{array}{c}\text { Density } \\
\left(\mathrm{Kg} / \mathrm{m}^{3}\right)\end{array}$ & Element \\
\hline $\begin{array}{l}\text { Open/close } \\
\text { frame }\end{array}$ & $3.90 \mathrm{E}+10$ & 0.2 & 2400 & beam44 \\
$\begin{array}{l}\text { sluice pier } \\
\text { baseboard }\end{array}$ & $3.71 \mathrm{E}+10$ & 0.167 & 2400 & solid65 \\
$\begin{array}{l}\text { weak-weath } \\
\text {-ered rock }\end{array}$ & $3.38 \mathrm{E}+10$ & 0.167 & 2400 & solid 65 \\
sluice gate & $2.90 \mathrm{E}+9$ & 0.3 & 2600 & solid 65 \\
\hline
\end{tabular}

The representative value of water pressure along the river, which is acted on the sluice gate, can be calculated as follows.

$$
P_{w}(h)=\frac{7}{8} a_{h} \rho_{w} \sqrt{H_{0} h}
$$

It can be converted to the corresponding added mass on the sluice surface and numerical simulated by MASS21 element ${ }^{[3]}$. The earthquake influence on uplift pressure, silt pressure and soil pressure, along with the dynamic water pressure by vertical earthquake, were all ignored in this paper.

The number of elements of the souring sluice with foundation model is totally 21322, with 25426 joints. Concern to the coordinate system, along the river to the downstream is $\mathrm{Z}$ axis positive, straight up is $\mathrm{Y}$ axis positive. In the ANSYS stress results, positive value is tensile stress, and negative value is pressure stress. The 3D ANSYS model is as Fig2.

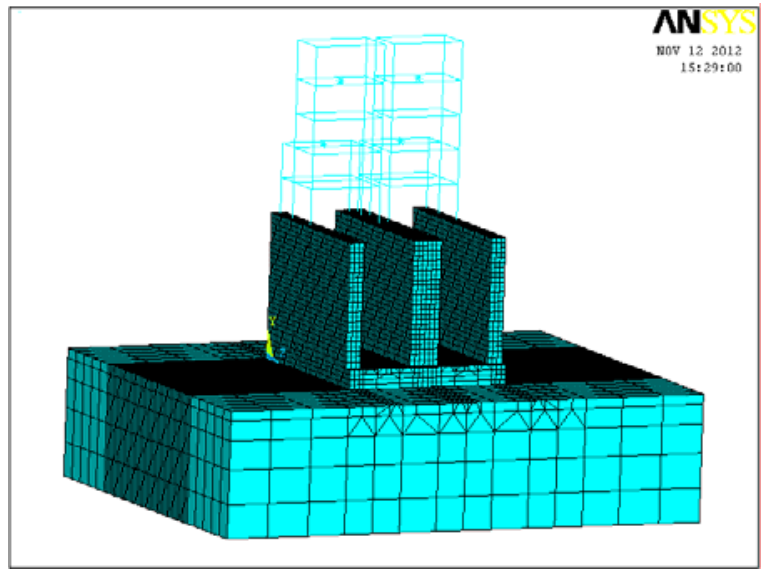

Figure 2. 3D finite element model of the souring sluice

\section{B. Mode analysis results}

According to the mode analysis results, first 4 orders were the main modes in the earthquake response. The effective mass ratio of first 4 orders reached $94.8 \%$, whereas, the first 8 orders of modes were extracted in the spectral analysis. The results indicated that the mode shape conformed to the general rules, as shown in Fig.3. No adverse mode shape appeared. The natural frequency of reservoir full is less than the reservoir empty. The first 8 orders of nature frequencies were listed in table 3.

TABLE III. FIRST 8 ORDERS NATURAL FREQUENCY OF SOURING SLUICE UNIT:Hz

\begin{tabular}{lcccccccc}
\hline Mode & 1 & 2 & 3 & 4 & 5 & 6 & 7 & 8 \\
\hline Full & 1.40 & 1.47 & 1.67 & 1.79 & 1.80 & 1.94 & 2.91 & 3.07 \\
Empty & 1.41 & 1.47 & 1.67 & 1.79 & 1.81 & 1.95 & 2.92 & 3.07 \\
\hline
\end{tabular}

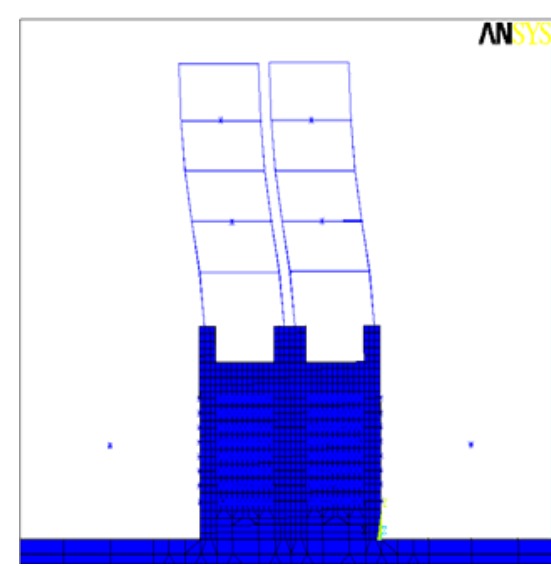

(a) First mode 


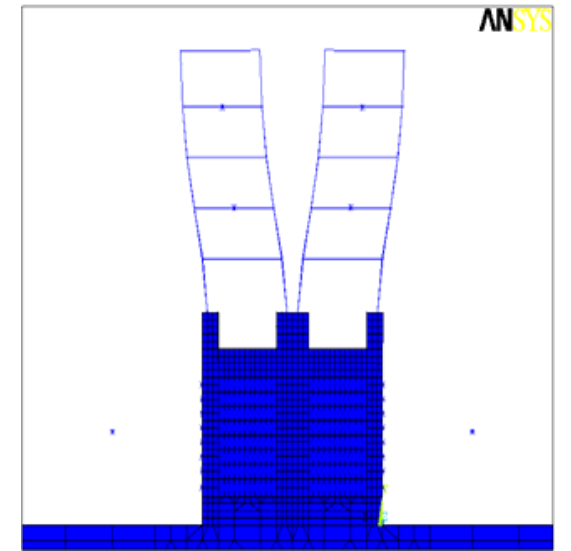

(b) Second mode

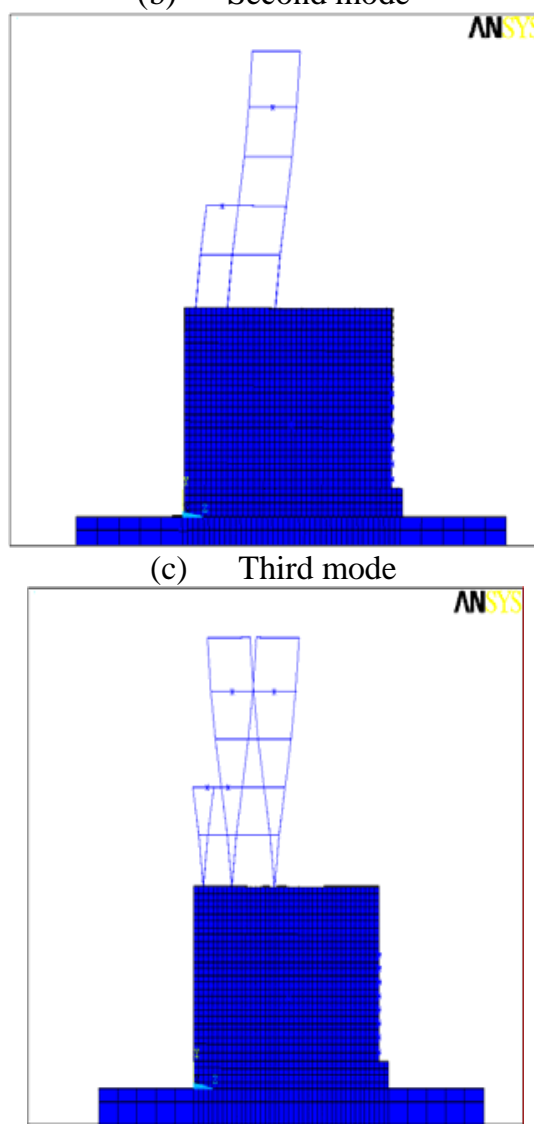

(d) Fourth mode

Figure 3. First 4 modes of the souring sluice

\section{ANSYS results}

During the calculation by ANSYS, 4 basic cases were considered: (1)Normal pool level; (2)Check flood level; (3)Frequently occurrence earthquake; (4)Rarely occurrence earthquake. The first 2 cases are static case, and the maximal displacement of the souring sluice under the case was listed in table4. To overall consideration on dynamic response of the sluice, the Case (1) and Case(3), the Case (1) and Case (4) were separately combined. The static and dynamic combined displacements of sluice were listed in table5. To reveal the weak parts of sluice pier and open/close frame, the maximum and position of major principal stress results were obtained, as shown in table 6, as well as the draft ratio of open/close frame shown in table 7.

TABLE IV. MAXIMAL DISPLACEMENT OF SLUICE PIER UNDER STATIC CASE UINT:MM

\begin{tabular}{ccccc}
\hline Case & \multicolumn{2}{c}{ Along the river } & \multicolumn{2}{c}{ Across the river } \\
position & maximum & \multicolumn{1}{c}{ position } \\
\hline (1) & 3.81 & $\begin{array}{c}\text { Sluice top of } \\
\text { middle pier }\end{array}$ & 8.82 & $\begin{array}{c}\text { Sluice top of side } \\
\text { pier in upstream }\end{array}$ \\
(2) & 3.39 & $\begin{array}{c}\text { Sluice top of } \\
\text { middle pier }\end{array}$ & 14.45 & $\begin{array}{c}\text { Sluice top of side } \\
\text { pier in upstream }\end{array}$ \\
\hline
\end{tabular}

TABLE V. STATIC AND DYNAMIC COMBINED DISPLACEMENTS OF SLUICE UNIT:MM

\begin{tabular}{|c|c|c|c|c|c|c|}
\hline \multirow{2}{*}{ Case } & \multicolumn{3}{|c|}{ Along the river $\mathrm{Z}$} & \multicolumn{3}{|c|}{ Across the river $\mathrm{X}$} \\
\hline & top & heel & toe & top & $\mathrm{h}$ & toe \\
\hline (1) + (3) & -0.20 & 0.12 & -0.13 & 34.56 & 28 & 28.55 \\
\hline (1)-(3) & -0.34 & -0.23 & -0.27 & -33.80 & -35 & -30.11 \\
\hline (1) + (4) & 0.70 & 0.07 & 0.25 & 52.51 & 31 & 32.95 \\
\hline (1)-(4) & -0.73 & -0.32 & 0.05 & -54.01 & -43 & -33.11 \\
\hline \multicolumn{7}{|c|}{$\begin{array}{l}\text { TABLE VI. MAXIMUM AND POSITION OF MAJOR PRINCIPAL STRESS } \\
\text { UNIT MPA }\end{array}$} \\
\hline \multirow{2}{*}{ Case } & \multicolumn{3}{|c|}{ Sluice Pier Stress } & \multicolumn{3}{|c|}{ Sluice Baseboard Stress } \\
\hline & \multicolumn{2}{|c|}{ maximum } & position & \multicolumn{2}{|c|}{ maximum } & position \\
\hline (1) & \multicolumn{2}{|c|}{2.982} & interior toe & \multicolumn{2}{|c|}{10.707} & bottom toe \\
\hline (2) & \multicolumn{2}{|c|}{5.233} & interior toe & \multicolumn{2}{|c|}{13.078} & bottom toe \\
\hline (3) & \multicolumn{2}{|c|}{6.872} & interior toe & \multicolumn{2}{|c|}{7.782} & bottom toe \\
\hline (1) + (3) & \multicolumn{2}{|c|}{4.795} & outside toe & \multicolumn{2}{|c|}{15.485} & bottom toe \\
\hline (1)-(3) & \multicolumn{2}{|c|}{-2.589} & interior toe & \multicolumn{2}{|c|}{3.590} & bottom toe \\
\hline (4) & \multicolumn{2}{|c|}{7.888} & outside toe & \multicolumn{2}{|c|}{9.441} & bottom toe \\
\hline (1) + (4) & \multicolumn{2}{|c|}{5.160} & outside toe & \multicolumn{2}{|c|}{13.470} & bottom toe \\
\hline (1)-(4) & \multicolumn{2}{|c|}{-2.837} & interior toe & \multicolumn{2}{|c|}{5.148} & bottom toe \\
\hline
\end{tabular}

TABle VII. The Draft Ratio Results Of Open/Close Frame

\begin{tabular}{lcccc}
\hline \multirow{2}{*}{ Story } & \multicolumn{2}{c}{ Case (1) $\pm(3)$} & \multicolumn{2}{c}{ Case (1) $\pm(4)$} \\
& $\mathrm{X}$ & $\mathrm{Y}$ & $\mathrm{X}$ & $\mathrm{Y}$ \\
\hline 5 & $1 / 1874$ & $1 / 1732$ & $1 / 1405$ & $1 / 1299$ \\
4 & $1 / 1978$ & $1 / 1852$ & $1 / 1484$ & $1 / 1389$ \\
3 & $1 / 1863$ & $1 / 1480$ & $1 / 1397$ & $1 / 1110$ \\
2 & $1 / 1988$ & $1 / 1314$ & $1 / 1491$ & $1 / 986$ \\
1 & $1 / 2461$ & $1 / 831$ & $1 / 1845$ & $\mathbf{1 / 6 2 4}$ \\
\hline
\end{tabular}

\section{CONCLUSIONS}

According to the numerical simulation results, the seismic performance is well satisfied. For the sluice pier, the sides both within and outside of toe are the weak parts. 
For baseboard, the toe is also the weak part. And for open/close frame, the bottom story is the weak floor. All the above mentioned positions are worth to pay close attention in the design.

\section{V.ACKNOWLEDGMENTS}

The research work was supported by National Natural Science Foundation of China under Grant No. 51308094, No. 51308095 and No. 51278091.

\section{REFERENCES}

[1] Specification for Seismic Design of Hydraulic Structure (DL5703-2001). The State Economic and Trade Commission of China, 2001. (in Chinese)

[2] Xiong Bobo, Tian Bin, Sunzhenghua. Influence of Foundation Elastic Modulus on Stress and Displacement of Arch Dam. Water Resources and Power. 31(1), pp.10-18,2013. (in Chinese)

[3] Su Hexian, Pan Wen, Yang Jianrong, Lai Zhengcong. Study on Seismic Performance of the Non-overflow Gravity Dam [J]. Science Technology and Engineering,10(26), pp.77-83,2010. (in Chinese) 